\title{
STUDI PERENCANAAN DINDING PENAHAN TANAH TIPE GRAVITASI MENGGUNAKAN PROGRAM GEO5
}

\author{
Ezral Dwi Prayogi Sambo \\ Program Studi Teknik Sipil Universitas Muhammadiyah Sorong \\ Jalan Pendidikan No 27 Kota Sorong, Propinsi Papua Barat \\ Email : ezralps28@gmail.com
}

\begin{abstract}
ABSTRAK
Tanah sebagai material konstruksi sekaligus tanah sebagai dasar pondasi dari suatu konstruksi seperti embung yang ada pada lokasi embung majaran distrik salawati kabupaten sorong. Studi ini bertujuan untuk merencanakan dimensi dinding penahan tanah yang stabil terhadap stabilitas pergeseran, penggulingan, dan daya dukung dengan merencanakan Dinding Penahan Tanah Tipe gravitasi yang diefisienkan menggunakan program Geo5.

Perhitungan tekanan tanah dihitung dengan menggunakan Teori Rankine serta menghitung kestabilan terhadap keruntuhan kapasitas dukung tanah di hitung berdasarkan persamaan Hansen dan Vesic berdasarkan data-data karakteristik tanah dari pengujian tanah di laboratorium mekanika tanah Teknik Sipil Universitas Muhammadiyah Sorong untuk mengetahui nilai ( c dan Ø).
\end{abstract}

Kata Kunci : Perencanaan Dinding Penahan Tanah Tipe Gravitasi, Uji Geser Langsung, Software Geo5. 
PENDAHULUAN

\section{Latar Belakang}

Kabupaten Sorong merupakan salah daerah yang terletak di Papua Barat. Keadaan topografi Kabupaten Sorong sangat bervariasi terdiri dari pegunungan, bukit-bukit, lereng, dan sebagian adalah dataran rendah. Kabupaten Sorong juga merupakan salah satu daerah yang sebagian penduduknya adalah petani. Oleh karena itu banyak embung dan bendungan yang sudah dibangun sebagai penampungan air agar di alirkan ke berbagai daerah pertanian yang ada di Kabupaten Sorong.

Salah satu embung yang ada di Kabupaten Sorong terletak di Kelurahan Majaran Distrik Salawati. Embung ini berguna sebagai penampungan air yang nantinya akan dialirkan ke daerah sekitar saat dibutuhkan. Sebagian besar warga di Kelurahan Majaran merupakan petani. Kendala utama yang dihadapi oleh petani di daerah tersebut adalah kesulitan dalam mendapatkan air untuk bercocok tanam. Oleh karena itu, embung yang terletak di kelurahan Majaran ini diharapkan dapat membantu petani didaerah tersebut dalam mengatasi masalah kesulitan air.

Embung Majaran terletak di sekitar lereng dan bukit yang kondisinya tidak diberi perkuatan. Hal ini tentu dapat menjadi masalah besar pada embung. Kondisi embung tidak boleh terganggu oleh tanah agar tidak terjadi penimbunan tanah yang dapat mengakibatkan tertutupnya daerah aliran air. Bila hujan secara terus-menerus, dapat mengakibatkan terjadinya keruntuhan tanah pada lereng dan bukit yang ada di sekitar embung.

Salah cara untuk mengatasi terjadinya keruntuhan tanah pada embung Majaran adalah membangun dinding penahan tanah. Pada kondisi ini peneliti mencoba merencanakan dinding penahan tanah type gravitasi karena lereng yang terletak disekitar embung memiliki tinggi tidak lebih dari 6 meter.

Saat ini teknologi terus berkembang pesat. Penggunaan program sebagai alat bantu dalam dunia konstruksi juga semakin banyak. Peneliti merasa bahwa perlu adanya perbandingan hasil perhitungan manual dan menggunakan program. Program yang dipakai adalah GEO5. GEO5 adalah program yang dibuat untuk membantu memecahkan berbagai masalah geoteknik dengan cepat dan akurat.

\section{Tujuan Penelitian}

Penelitian ini bertujuan untuk menganalisa gaya - gaya yang bekerja pada dinding penahan tanah tipe gravitasi secara manual dan menggunakan Geo5.

\section{STATE OF THE ART}

Adapun penelitian terdahulu yang terkait dengan penelitian ini adalah sebagai berikut :

1. Menurut Sriyanti Ramadani (2010) menyatakan bahwa nilai stabilitas guling fgl = 3,6 < 1,5 aman, gaya geser fgs $=1,5<1,5$ aman, dan daya dukung tanah $\mathrm{F}=14,587<3$ aman, serta penurunan sebesar $=$ $0,026 \mathrm{~cm}$.

2. Menurut Arya Nugraha (2013) menyatakan Hasil analisis tersebut dapat dilihat sebagai berikut :

1) Hasil Perhitungan manual :
a) faktor stabilitas terhadap geser 2,475 $>2$
(aman)
b) stabilitas terhadap guling 3,945>2
(aman)
c) keruntuhan kapaitas daya dukung $4,874>3$
(aman)

2) Hasil perhitungan program Geo5:

a) stabilitas terhadap guling $2,01>2$

(aman)

b) stabilitas terhadap geser 2,32>2

(aman)

c) keruntuhan kapasitas daya dukung 5,11 > $\quad$ (aman)

3. Menurut Gutama Rymo Kisworo (2014) menyatakan Hasil analisis tersebut dapat dilihat sebagai berikut :

1) Hasil Perhitungan manual :

a) faktor stabilitas terhadap geser $5,042>2$

(aman)

b) stabilitas terhadap guling 19,29>2

(aman) 
c) keruntuhan kapaitas daya dukung 2,010>2 (aman)

2) Hasil perhitungan program Geo5:

a) stabilitas terhadap guling 16,88 $>2 \quad$ (aman)

b) stabilitas terhadap geser $5,58>2 \quad$ (aman)

c) keruntuhan kapasitas daya dukung 2,77 > $\quad$ (aman)

\section{METODE}

\section{Tahapan Penelitian}

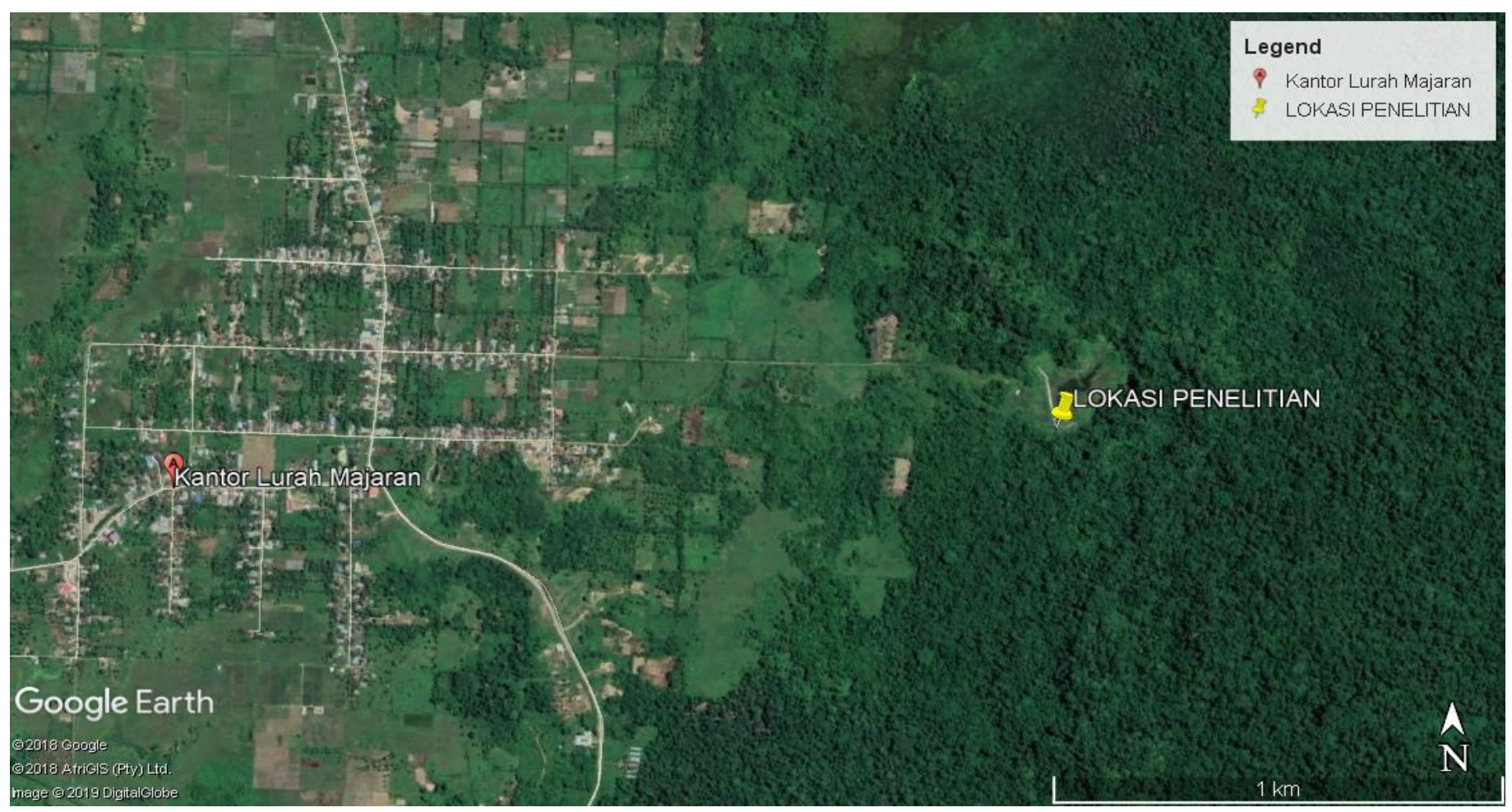

Tahapan penelitian yang digunakan adalah sebagai berikut :

1. Melakukan pengambilan sample terhadap Lereng yang berada diatas embung pada Distrik Salawati, Kelurahan Majaran Kabupaten Sorong.

2. Mengolah data tanah dari hasil yang telah di dapatkan pada saat melakukan pengambilan sample secara langsung .

3. Mengidentifikasi dan menganalisa stabilitas terhadap guling, geser dan daya dukung pada lereng diatas embung distrik salawati kabupaten sorong.

Semua metode penulisan dan analisa dalam artikel ilmiah ini merujuk pada panduan penulisan tugas akhir Fakultas Teknik Universitas Muhammadiyah Sorong tahun 2014 (Pristianto, Amri, \& Rusdi, 2014). 


\section{REFERENSI}

1. Rohman, 2017,Modul Pratikum Mekanika Tanah,Universitas Muhammadiyah Sorong

2. G. Djatmiko Soedarmo,S. J. Edy Purnomo, 1997, Mekanika Tanah 1, Yogyakarta: Penerbit Kanisius.

3. Hary Cristady Hardiyatmo, 2010, Mekanika Tanah II,Edisi V, Yogyakarta: Penerbit Universitas Gadjah Mada.

4. Hary Cristady Hardiyatmo, 2002, Teknik Pondasi 1 Edisi ke-2, Yogyakarta: Beta Offset.

5. Braja M. Das, 1995, Mekanika Tanah 1, Jakarta: Penerbit Erlangga.

6. Sriyati Ramadhani." Perencanaan Dinding Penahan Tipe Gravitasi Pada Lokasi Bukit Btn Teluk Palu Permai 2010"

7. Arya Nugraha." Perencanaan Dinding Penahan Tipe Gravitasi Dengan Menggunakan Program Geo5 pada jalan Piyungan-Batas Gunung Kidul 2013"

8. Gutama Rymo Kisworo.” Perencanaan Dinding Gravitasi dengan Program Geo5 pada proyek gedung bank mandiri Jl. Brigden Slamet No.241,Solo Jawa Tengah 2014"

9. Jumri." Perencanaan Dinding Penahan Tanah pada ruas jalan tenggarong seberang km 10 kecamatan tenggarong seberang 2015"

10. Engineering manuals for GEO5 programs manual no.3/2018 